\title{
Fieldwork Experience as Cultural Immersion: Two International Students and Their Professor Reflect on a Recent Evaluation Practicum
}

\author{
Grettel Mariana Arias Orozco \\ University of North Carolina, Greensboro / Universidad de Costa Rica \\ Onyinyechukwu Onwuka du Bruyn \\ University of North Carolina, Greensboro \\ Jill Anne Chouinard \\ University of Victoria
}

\begin{abstract}
In this practice note, two international students of evaluation reflect on the cultural challenges they experienced learning to apply Western-based methodologies in unfamiliar cultural contexts. Using a process of reflection, the students identify four interrelated challenges: understanding the culture and program setting, the need for interpersonal and communication skills, learning the language of evaluation, and telling the story. The paper concludes with reflections from the course professor, who highlights the challenges of teaching evaluation, an intensely cultural practice with deep roots in Western theoretical traditions, to students who do not come from the United States. Through reflective practice, the two students were able to overcome many of their initial challenges.
\end{abstract}

Keywords: cultural immersion, evaluation practicum, international students, reflective journal, teaching evaluation

Résumé : Dans la présente note sur la pratique, deux étudiantes étrangères en évaluation réfléchissent aux défis culturels rencontrés en cours d'apprentissage en ce qui concerne l'application de méthodologies occidentales dans des contextes culturels non familiers. À l'aide d'un processus de réflexion, les étudiantes cernent quatre défis interdépendants soit : la connaissance de la culture et du cadre du programme; l'importance de compétences interpersonnelles et de communication; lapprentissage de la langue de l'évaluation et la narration du récit. L'article se termine par les réflexions de la professeure du cours, qui met en évidence les défis liés à l'enseignement de l'évaluation, une pratique intensément culturelle et profondément enracinée dans les traditions théoriques occidentales, à des étudiants qui ne viennent pas des ÉtatsUnis. Par une pratique réflexive, les deux étudiantes ont pu surmonter bon nombre de leurs défis initiaux.

Corresponding author: Grettel Mariana Arias Orozco, Department of Educational Research Methodology, School of Education, University of North Carolina, Greensboro, 1300 Spring Garden Street, Greensboro, NC, 27412; gmariaso@uncg.edu. 
Mots clés : immersion culturelle, stage d'évaluation, étudiants étrangers, journal de réflexion, enseignement de l'évaluation

The challenges of helping students transition from classroom-based learning to an applied field setting have been well documented (e.g., Buitrago et al., 2015; Gredler \& Johnson, 2001; Hurley et al., 2005; Perry, 2008), underscoring the fact that evaluation is more than a technical craft and requires more than the application of methodological expertise (Chouinard et al., 2017). While evaluation contexts are complex, multifaceted, and highly interactive spaces that encompass a blend of social, historical, political, and cultural dimensions (Mathison, 2005), learning evaluation can itself be a tumultuous, uncertain, and daunting experience for many students (Chouinard et al., 2017; Hurley et al., 2005), not least for those from other countries.

In this practice note, two international students (one from West Africa and the other from Latin America) reflect on their first evaluation experiences gained through an evaluation practicum course, with a focus on the challenges and opportunities they encountered throughout. The course professor, responsible for selecting projects and providing guidance to students during the course of the semester, concludes with further reflections on teaching an applied evaluation practicum to international students. In the first part of this paper, we describe the evaluation course and the program context. The second part focuses on four identified challenges: immersion in understanding the culture and program context, the need for interpersonal and communication skills, learning the language of evaluation, and telling the story. The course professor concludes with reflections about the students' perspectives and the challenges of teaching evaluation to international students.

\section{A DESCRIPTION OF THE UNIVERSITY COURSE AND THE PROGRAM CONTEXT}

The graduate degree in program evaluation begins with an evaluation theory course in which students first learn about the basic concepts, theories, and models of evaluation. The goal of the course is to enable students to understand the major theories and approaches used in evaluation, develop an evaluation plan (based on a case study), and identify the different components of an evaluation. The process of determining which approach to use in a specific context is highlighted throughout, as are the different research paradigms and contexts of practice. This course is followed by a practicum course, where students pair off into small teams to collaboratively plan and conduct a small-scale evaluation, which they complete during the semester (January to April). This course provides students with practical experience conducting and managing a small-scale evaluation, designing a context-appropriate evaluation, applying basic data-collection tools, analyzing qualitative and/or quantitative data, and writing a final report. During the semester we focus on here, six students were enrolled in the course, with three evaluation teams working on separate program evaluations. Weekly in-class 
discussions facilitated by the professor encouraged peer learning, while scheduled one-on-one sessions ensured that students were on track. As part of the course, we were required to keep reflective journals with weekly entries throughout the semester; these provided us the opportunity to record our experiences conducting the evaluation, to reflect on our experiences as novice evaluators, and to document our insights, challenges and expectations. We used these journal entries for further discussion and to assist with our thematic analysis.

For our evaluation, we selected a principal preparation program situated within the university, a program that involves a partnership with 11 rural school districts that struggle to find and keep effective principles for high-needs schools. The goal of the partnership is to develop strong, sustainable leadership pipelines within those 11 districts, and prepare and license 20 new principals for highneeds, rural schools. Year one of the program involves rigorous coursework with a site-based practicum in a high-needs, rural school, followed by a full-time, 10 -month internship in year two with a principal as mentor at a high-needs school. The evaluation we designed was formative and based on qualitative data collection, with a focus on understanding program coherence through the diverse learning experiences of program participants. We worked closely with the project director throughout our evaluation and were fortunate that she had the time to devote to our understanding of the program context.

\section{THE STUDENTS' PERSPECTIVES}

Analysis of our respective journals and further collaborative reflection led us to identify four interconnected challenges that we believe capture our experiences as international students learning about evaluation within the cultural context of the United States. The four challenges are understanding the culture and program setting, the need for interpersonal and communication skills, learning the language of evaluation, and telling the story.

\section{Understanding the culture and program context}

When we began this evaluation, we had only recently arrived in the United States and had only a limited understanding of evaluation. One of the first things we were taught about evaluation was the importance of understanding context. As international students new to the United States and to the field of evaluation, we found this a significant challenge, as it meant learning not only about the program and its local context but also about the US education system, a system very different from the ones in our home countries. Specifically, we could not understand why there would be an issue retaining rural principals, the very objective of the program we were tasked to evaluate. In Costa Rica, the salary of teachers and principals is based on their formal education and their previous classroom experience. When teachers and principals go to rural parts of the country, they receive an incentive rather than a decrease in their salaries. Similarly, in Nigeria, the salary of principals and teachers is based on their qualifications and on the 
tier of government (local, state, or federal) that has employed them. Principals and teachers employed in schools managed by the federal government earn more money than their state or local colleagues.

To learn more about the specific context of the program, we had to devote a significant amount of time reading and learning about high-needs rural schools in the United States and about the challenges of retaining school personnel. We had a difficult time finding the information we needed about the US education system, specifically information about salaries for teachers and principals in rural communities and about other relevant policies. This research added another layer of complexity to the task of learning how to do evaluation in a short, one-semester time period. Program documentation was our main source of information, but we also consulted peer-reviewed articles and had numerous discussions with colleagues in our department who shared knowledge about the local education system.

Given that we felt like "outsiders" to the program and to the culture of the community, we reflected regularly on what we considered our potential biases, checked our assumptions with stakeholders and participants, and practiced active listening. Throughout, we were keenly aware of our positionality and practiced humility by knowing we were learning about the program, the culture, and program evaluation at the same time; we were also respectful of cultural habits and customs (e.g., being punctual, addressing our stakeholders by their names/ titles, pronouncing their names correctly, and respecting their schedules). With more time, we believe we would have been able to gain more insight about the program and program context, which we believe would have made our evaluation stronger.

\section{The need for interpersonal and communication skills}

Strong interpersonal and communication skills are extremely important when working with clients to help establish strong partnerships and facilitate ongoing dialogue. We consider this our second challenge. None of the courses we had taken before the applied evaluation class had addressed these topics in any detail. As a result, we felt we needed to learn more about teamwork, conflict resolution and negotiation, and problem solving and decision making prior to this applied evaluation course. In our discussion of this challenge we realized that our concern was with our use of language and with trying to figure out how best to communicate with our client and with program participants. We spent a significant amount of time discussing how to best reach our client (phone call, email, or face-to-face), and how to write and compose all communications. In addition to being from different countries and different backgrounds, one of us is not a native English speaker. Communication and use of language were thus an ongoing concern, especially as we wanted to project professionalism in our practice as novice evaluators. While we believe that, overall, we did a good job communicating with our client, we cannot overemphasize the need for formal training in interpersonal and communication skills, especially for novice evaluators. From the perspective 
of international students, we believe these skills are even more important, as we have not yet learned the rules and norms of dialogue and communication in the United States.

\section{Learning the language of evaluation}

Language was a critical element of our applied evaluation experience. As mentioned previously, for one of the international evaluators, English is her second language. As a result, besides the necessity for cultural competence, linguistic (literal and figurative language) and pragmatic competences were essential. To communicate effectively, we tried to engage in clear and transparent dialogue, avoiding the use of slang and idioms and asking for explanations with acronyms or uncommon phrases when necessary. Given the importance of language, we were very careful with how we constructed emails to stakeholders and participants, working to ensure clarity; this was especially important given that we come from different cultures and that a word in our culture could mean something totally different in an American context. In Costa Rica, for example, the terms assessment and evaluation are encompassed within one umbrella term, "evaluación."

We also realized that, by learning evaluation in the United States, we were at the same time being immersed in the Western canon, in a very specific way of knowing, and with very specific views, beliefs, values, methods, and language. Learning about evaluation in the southeastern United States also meant learning about racial diversity and discrimination, two discourses that are not as prevalent in our home countries, given the homogeneity of people in Costa Rica and Nigeria. Where we come from, discussions are more commonly focused on financial disparities, unemployment, crime, violence, environmental problems, and the government's lack of capacity. These ideological discourses emphasize specific aspects, topics, or problems as they are conceptualized within a specific society, and these concepts shaped and influenced what we learned. This was a crucial acknowledgement for us, as language shapes our understanding of the methods and theories we use, reflects a point of view, and shapes how we think and what we think about. Consequently, we remained aware of what our language revealed and what it occluded, whom it omitted and whom it embraced - all very important as we sought to represent a diversity of stakeholder perspectives throughout our evaluation.

From a broader perspective, language was particularly important for us because we understand language as a performative act (Austin, 1975; Searle, 1969). Through language, we not only express actions and realities but also create them. From this point of view, language is closely related to culture and identity since language shapes our realities. In our evaluation, we were interested in how our spoken and written utterances could affect the circumstances in which the evaluation was taking place, how the language we used could alter participants' reality, and in what ways we were interpreting and communicating this in our final report. We understand the power of our language and words, especially as we are "outsiders" in a system of thought and practice that is so firmly entrenched in the American setting. 


\section{Telling the story}

Our final challenge focuses on the challenges we experienced reporting our evaluation findings and "telling the program's story," as we were instructed to do by our professor. As international students, we were confused about how to tell our program's story and to write a convincing narrative that would capture everything we had learned through our evaluation. Although we consulted multiple sources and studied multiple examples of final reports, they all used language differently and contained different sections and subsections and different ways of visualizing data. As a result, we constantly questioned our telling of the story and kept looking for a better way to narrate our findings and to include all the different voices and perspectives of our participants. After multiple iterations, we decided to use a three-step approach to telling the story: (1) exploring the data with the evaluation framework in mind, (2) turning the findings from this exploration into a narrative or story, and (3) communicating this narrative to our stakeholders in the form of an evaluation report. Constant communication and engagement with the client were essential in our learning process.

Regardless of the context, we recognized that acknowledging our biases, values, and positionality plays an important role in how we tell the story. Researchers and evaluators are part of a privileged group with the power to shape meaning and construct knowledge. Looked at in a certain way, the discipline of evaluation is nonfiction story making, where our stories are considered "facts." Given this, we believe that evaluators must be attentive to misinterpretation or misrepresentation, especially since this may have very real implications in people's lives. The fact that we come from different countries and different cultures merely adds to the importance of reflecting upon our subjectivity (Pon, 2009), a reflection we now realize helped us navigate the complexity of this cultural context.

To conclude, we consider openness, flexibility, and humility to be key components of our profession, and essential in enabling us as international students to address the many challenges we experienced. Evaluation work requires us to reflect on and be aware of our cultural identity in order to ground our positionality, assumptions, and biases. Our recommendation to other international students is to act consciously, to keep learning, reflecting on, and thinking about culture (yours and others), and to keep an open appreciation and respect for divergent worldviews. Reflective practice can help us navigate complex contexts. Finally, we recommend that professors who teach evaluation to international students be aware of cultural differences, language barriers, and the immersion process, and that they look beyond the application of their frameworks and perspectives to understand that there is no one unique approach for doing evaluation, but many, depending upon the program and its cultural context.

\section{THE COURSE PROFESSOR RESPONDS}

The two international students identify four challenges that they experienced conducting their first field evaluation. They note specific challenges: understanding 
the cultural context of the program, the need for solid interpersonal and communication skills, the need for understanding the language of evaluation, and challenges with interpreting data and presenting the final results. Their discussion of "telling the program's story" illustrates many of these challenges, as it involves language, interpretation, and positionality, all key concerns in any evaluation. Their conclusion highlights the need for reflective practice, an especially important "reflection in action" (Schon, 1983) perspective for novice evaluators who are transitioning from the safety of the classroom to the field of practice. While these four challenges can be understood from the perspective of international students-that is, from a cultural perspective and as issues of language and translation-they are also shared by novice evaluators who come from the United States. In prior research (see Chouinard et al., 2017), we noted that students who were novice evaluators struggled with understanding the socio-political dynamics of program contexts and the need for reflective and adaptive practice throughout the evaluation process. Interestingly, the challenges of practice led these students to seek the safety of evaluation theory, which unfortunately did not provide the comfort (or answers) they sought. The international students, as we learn from their narrative, did not look to evaluation theory for answers to their field challenges. Instead, they sought a more thorough understanding of the program's context. Their four challenges represent what many evaluators struggle with throughout the evaluation process. Can we ever say we understand a program's context? How do we position ourselves in reference to the community and to the program? Are we insiders or outsiders? How do we ensure and maintain excellent communication with clients and stakeholders? How can we practice cultural humility? Do our interpretations make sense? The students' challenges, their questions, and their conclusions about reflective practice all point to examples of good evaluation practice.

Evaluation is an intensely cultural practice founded on principles of Western modernity, rationality, and progress (Bhola, 2003; L. T. Smith, 1999). As a teacher in this course, especially as a teacher of international students, I was keenly aware of my positionality and academic privilege, my Western perspectives and biases, my colonizing act of promulgating frameworks, theories, and concepts that are fundamentally rooted in Western epistemology, ideology, and privilege, and the challenges these students would likely experience adapting Western-based methodologies to their local program and community contexts once they return home. Evaluation, as we understand and practice it, is very much a Western concept (Bhola, 2003; Hopson, 2003), a concept the West has been exporting to the Global South for many years. Exporting our Western-based approaches and methodologies is merely another form of colonial rule, albeit in the form of evaluation and knowledge production. I thought about Carden and Alkin's (2012) notions of adopted and adapted methodologies, as it highlights the shift to approaches that are tailored to local socio-cultural, political, economic, and ecological contexts. At the very least, it signifies a move toward epistemologies that are local and culturally relevant to the people and programs they are intended to represent. That was 
my goal (and also my challenge) as I stood in front of the room in early January, acutely aware that these students would have only four months in which to conduct their first evaluation, as many of them continued to struggle with building logic models, analyzing qualitative data, writing a survey, and so on. Teaching is a daunting task, and teaching evaluation as a socio-cultural and Western political construct remains even more daunting. Would these international students be able to adapt our Western-based methodologies once they got home? As Nick Smith (2002) asks, if we, as teachers of evaluation, are unfamiliar with the home cultures of our students, how do we prepare them to translate Western-based evaluation theories into their own local contexts? In the end, I believe that it was through their queries, inquisitiveness, and uncertainties, and through their acts of bravery, that these two international students were able to overcome their challenges and become reflective practitioners.

\section{REFERENCES}

Austin, J. L. (1975). How to do things with words. Oxford University Press.

Bhola, H. S. (2003). Social and cultural contexts of educational evaluation: A global perspective. Kluwer.

Buitrago, C., Bhalla, S., Davidson, N., Davila, S., Hinojosa, A., Liberman, B., \& Tosh, K. (2015). Learning for all: The value of field experiences in training a new generation of program evaluators. Harvard Family Research.

Carden, F., \& Alkin, M. C. (2012). Evaluation roots: An international perspective. Journal of Multidisciplinary Evaluation, 8(17), 108-118.

Chouinard, J. A., Boyce, A. S., Hicks, J., Jones, J., Long, J., Pitts, R., \& Stockdale, M. (2017). Navigating theory and practice through evaluation fieldwork: Experiences of novice evaluation practitioners. American Journal of Evaluation, 38(4), 493-506. https://doi. org/10.1177/1098214016667582

Gredler, M. E., \& Johnson, R. L. (2001). Lessons learned from the directed evaluation experience. American Journal of Evaluation, 22(1), 97-104. https://doi.org/10.1016/ S1098-2140(01)00115-1

Hopson, R. K. (2003). Overview of multicultural and culturally competent program evaluation: Issues, challenges andopportunities. Social Policy Research Associates. California Endowment.

Hurley, C., Renger, R., \& Brunk, B. (2005). Learning from a challenging fieldwork evaluation experience: Perspectives of a student and an instructor. American Journal of Evaluation, 26(4), 562-578. https://doi.org/10.1177/1098214005281323

Mathison, S. (Ed.). (2005). Encyclopedia of evaluation. Sage.

Perry, K. M. (2008). A reaction to and mental metaevaluation of the experimental learning evaluation project. American Journal of Evaluation, 29(3), 352-357. https://doi. org/10.1177/1098214008321686

Pon, G. (2009). Cultural competency as new racism: An ontology of forgetting. Journal of Progressive Human Services, 20(1), 59-71. https://doi.org/10.1080/10428230902871173 
Schon, D. (1983). The reflective practitioner: How professionals think in action. Basic Books.

Searle, J. R. (1969). Speech acts: An essay in the philosophy of language. Cambridge University Press.

Smith, N. L. (2002). International students' reflections on the cultural embeddedness of evaluation theory. American Journal of Evaluation, 23(4), 481-492. https://doi. org/10.1016/s1098-2140(02)00232-1

Smith, R. A., \& Khawaja, N. G. (2011). A review of the acculturation experiences of international students. International Journal of Intercultural Relations, 35(6), 699-713. https://doi.org/10.1016/j.ijintrel.2011.08.004

\section{AUTHOR INFORMATION}

Grettel Mariana Arias Orozco is affiliated with both the Universidad de Costa Rica (UCR) and the University of North Carolina Greensboro (UNCG), where she is an international student currently pursuing her Ph.D. in educational research methodology (ERM), with a concentration on program evaluation. Throughout her MS/Ph.D. education, her research focus has centred on researching international students' experiences studying evaluation in the United States, evaluating STEM projects and programs serving historically marginalized populations and, most recently, reflections about the use of culturally relevant methodologies when doing evaluations with Latino populations and by Latino evaluators.

Onyinyechukwu Onwuka du Bruyn has ten years of experience as a research methodologist and statistician. She is currently a Ph.D. student in the Department of Educational Research Methodology (ERM) at the University of North Carolina, Greensboro (UNCG), studying program evaluation. She is passionate about gender equality and surfacing women's voices in research. Her research interests center on employing a culturally responsive approach to evaluation and utilizing the social justice lens in conducting evaluation in marginalized and under-represented communities and populations. She has managed several public health and edutainment research projects in Nigeria funded by UNICEF, USAID, and the World Bank.

Jill Anne Chouinard is an associate professor in the School of Public Administration at the University of Victoria. Much of her evaluation work has been conducted in culturally and socially diverse community settings, where she has extensive experience leading evaluations at the community level in the areas of education, social services, public health, and organizational learning and change. She positions evaluation as a catalyst for learning, collaboration, equity, social justice, and community change. 